\title{
Systematic reviews on selected nutrition interventions: descriptive assessment of conduct and methodological challenges
}

\author{
Rehana A Salam¹, Vivian Welch² and Zulfiqar A Bhutta ${ }^{1,3^{*}}$
}

\begin{abstract}
Background: Rigorous and transparent systematic reviews are recognized internationally as a credible source for evidence of effectiveness. However, in the field of nutrition, despite attempts at developing consensus on actions and interventions to reduce undernutrition and micronutrient deficiencies, there is lack of coordination among various groups.
\end{abstract}

Methods: The aim of this overview of systematic review is to assess the process and conduct of systematic reviews published in the past 5 years to make recommendations on improving process and methodology of systematic reviews in the field of nutrition. We identified nine interventions from four areas of nutrition through a consultative process and conducted a comprehensive search to identify systematic reviews on the selected interventions published in the last 5 years.

Results: We identified 90 systematic reviews across these nine intervention areas. The median overall Assessment of Multiple Systematic Reviews (AMSTAR) score was 8 (range 2-11) with methodological quality of Cochrane reviews being fairly consistent with a median AMSTAR score of 10 (range 8-11), while for the non-Cochrane reviews, it ranged from 2 to 11 with a median of 7.5. From the 11-point AMSTAR criteria, 91\% of the reviews followed an a priori design, $81 \%$ did duplicate screening and data extraction, $88 \%$ conducted a comprehensive search, $64 \%$ used status of publication as an inclusion criteria, $44 \%$ provided the list of included and excluded studies, $60 \%$ assessed and documented the scientific quality of the included studies and used it in interpreting the results, $61 \%$ used appropriate methods to combine the results, $40 \%$ assessed publication bias and $82 \%$ stated the conflict of interest. We found considerable variation in methodological quality, lack of standardization of outcomes, lack of standardized assessment of risk of bias of included studies, variation in study designs included and variation in how heterogeneity was handled.

Conclusions: Each of these methodological choices influences the findings of the reviews, and lack of standardization across these domains increases the complexity for users of systematic reviews in interpreting results. There is a need to develop a consensus on methodologies for nutrition reviews, criteria for assessing the evidence and possibly facilitating development and collation of the evidence in the subject area.

Keywords: Systematic reviews, Nutrition, Methodological assessment

\footnotetext{
* Correspondence: zulfiqar.bhutta@sickkids.ca

${ }^{3}$ Robert Harding Chair in Global Child Health and Policy, Centre for Global

Child Health, The Hospital for Sick Children, Toronto, ON, Canada

${ }^{1}$ Center of Excellence in Women and Child Health, Division of Woman and

Child Health, Aga Khan University, Karachi 74800, Pakistan

Full list of author information is available at the end of the article
} 


\section{Background}

To reach the targets set for Millennium Development Goal (MDG) 1, which is to reduce extreme poverty and hunger by half, many countries are on-track in reducing the income poverty while less than a quarter of the developing countries are on-track for achieving the goal of halving undernutrition [1]. The global burden of undernutrition remains high with little evidence of change in many countries despite economic growth. Millions of people are faced with starvation and malnutrition; the State of Food Insecurity (SOFI) in the World 2012 estimated that about 870 million people have been undernourished (in terms of dietary energy supply) in the period 2010-2012, mostly from low-middle-income countries (LMIC) [2]. About one third of deaths in children under 5 years of age are due to underlying undernutrition, which includes stunting, severe wasting, deficiencies of vitamin $\mathrm{A}$ and zinc and suboptimum breastfeeding [3]. The majority of an estimated 178 million children under five suffering from stunting are in sub-Saharan Africa and South-central Asia [4]. Around 55 million children are wasted, 19 million of these are severely affected and at high risk of premature death [4]. Altogether, more than 3.5 million mothers and children under five die unnecessarily each year in LMICs due to the underlying cause of undernutrition [5]. With the existing burden of undernutrition, the problem of overweight and obesity among children is also on the rise. In 2011, globally, an estimated 43 million (7\%) children younger than 5 years were overweight, an increase from an estimated 28 million in 1990. This trend is expected to continue and reach a prevalence of $9.9 \%$ (64 million) in 2025 [6]. Many of the LMICs are said to have the double burden of malnutrition-continued stunting of growth and deficiencies of essential nutrients along with the emerging issue of obesity.

Although there have been several attempts at developing consensus on actions and interventions for nutrition, there is lack of coordination between various academic groups, United Nations (UN) and development agencies, and these are working in parallel silos. The Lancet Nutrition series in 2008 [7-11] and more recently in 2013 [6,12-14] are important attempts at bringing the field together; however, progress by countries has been slow and also hampered by the global increase in food and oil prices; climate change; unprecedented draughts and increased number of countries affected by fragility, conflict and emergencies. As per the World Bank in 2011, 33 countries fall in the fragile situations category as per the World Bank definition [15]. In addition, conflict and fragility also occur at the sub-national level within some strongly performing countries.

Systematic reviews and meta-analysis have become increasingly popular in evidence-based healthcare over the past two decades [16], although these have been evaluated for reliability since quite a long time [17-20]. Rigorous and transparent systematic reviews are recognized internationally as a credible source for evidence of effects and as the basis for evidence-informed policy and decisions $[16,21,22]$. Within the field of nutrition, systematic reviews have been used to answer many complex questions. A description of systematic review methodology with particular regard to the steps for performing systematic reviews and areas unique to the discipline of nutrition is already available, published by the US Agency for Healthcare Research and Quality (AHRQ) [23]. Furthermore, guidance on assessing equity for users and authors of systematic reviews of interventions has also been highlighted recently to improve the relevance of systematic reviews for both clinical practice and public policy-making [24]. However, several gaps pertaining to the conduct and methodological approaches still exists particularly with reference to nutrition interventions implemented through sectors other than health, such as agriculture, social welfare and trade.

Across nutrition-related systematic reviews, there is multiplicity of reviews in the same subject area with variability in methods such as intervention, target population comparison, outcomes and consideration of contextual variables related to nutritional interventions and outcomes. Additionally, with the increasing attention to social determinants, there is a need to bring in additional qualitative aspects to such reviews. The World Health Organization (WHO) has led the field with a series of activities geared towards development of nutrition policy guidelines based on the best evidence. In 2011, a new online resource, the electronic Library of Evidence on Nutrition Actions (eLENA), was launched that provides access to available sources of evidence and to $\mathrm{WHO}$ guidelines, as well as to ongoing clinical trials in the field of nutrition [25].

This overview of systematic reviews from the selected areas in nutrition was produced as a background document for a WHO-convened meeting on improving the quality of systematic reviews of nutrition [26]. The aim of this paper is to assess the process and conduct of systematic reviews (including systematic reviews and systematic reviews + meta-analysis) published in the past 5 years to make recommendations on improving process and methodology of systematic reviews in the field of nutrition.

\section{Methods}

We consulted the major stakeholders including leading academic groups engaged in systematic reviews, editors of the Cochrane and Campbell collaborations; International initiative for impact evaluation (3ie); UN agencies including the WHO, United Nations International 
Children's Emergency Fund (UNICEF), World Food Program (WFP) and Food and Agriculture Organization (FAO); International Food Policy Research Institute (IFPRI); and interested bilateral agencies including the Department for International Development (DFID), United States Agency for International Development (USAID), Norwegian agency for International Development (NORAD) and representatives from the Bill \& Melinda Gates Foundation to identify nine focused interventions under four umbrella areas for our review. These areas were selected based on consultations and WHO interests and included preventive (interventions to prevent undernutrition and micronutrient deficiencies), therapeutic (interventions to treat undernutrition and micronutrient deficiencies), food fortification strategies and delivery platforms (Table 1).

We defined systematic review according to the 'Cochrane Handbook of Systematic Reviews' [27] as 'A systematic review attempts to collate all empirical evidence that fits prespecified eligibility criteria in order to answer a specific research question'. Meta-analysis was defined as 'the use of statistical methods to summarize the results of independent studies'. An overview of systematic reviews was defined as 'Systematic and explicit methods to identify select and critically appraise relevant findings from systematic reviews and/ or metaanalysis of effectiveness of interventions'. We included systematic reviews of trials as well as observational studies. We considered all available systematic reviews and overviews of systematic reviews on the predefined interventions. A separate search strategy was developed for each intervention using preidentified Medical Subject Headings $(\mathrm{MeSH})$ and key search terms. A search was conducted in the Cochrane Library, Campbell Collaboration, PubMed and Google Scholar to identify systematic reviews in each of the nine intervention areas. Additional reviews were identified by hand searching references from included reviews. A priori inclusion criteria were outlined stated as below:

- Systematic reviews pertaining to effectiveness or efficacy of nutrition-related interventions, assessed by prospective studies (including both trials and observational studies), published between 2005 and 2011 were included.

- Overviews of systematic reviews were also included if they were found to be relevant.

- Reviews of all languages with English translations were considered eligible for inclusion.

- Inclusion was not restricted to any particular reported outcome.

Reviews that met the inclusion criteria were selected and double data abstracted on a standardized abstraction sheet for source journal, funding, authors, year, title, target population, intervention, study setting (high-income countries or low-middle-income countries) and comparison, outcomes, types of included studies (randomized trials, quasi trials, before-after, etc.), gaps in knowledge base (as identified by the author), and conclusions. Any disagreements on selection and abstraction of reviews between the two primary abstractors were resolved by the third reviewer. We also assessed each systematic review according to the components from the Cochrane Public Health Review Group guidance including study design; searching non-health databases; assessing risk of bias, ethics and inequality; context; sustainability and applicability [28]. For each systematic review, we assessed the quality of the review by the Assessment of Multiple Systematic Reviews (AMSTAR) rating consisting of 11 items which has been demonstrated to have good face and content validity for measuring the methodological quality of systematic reviews [29]. We then compared the reviews within the same

Table 1 Topic areas of landscape study

\begin{tabular}{|c|c|}
\hline Topic area & Interventions \\
\hline \multirow{4}{*}{$\begin{array}{l}\text { Preventive nutrition interventions (interventions to prevent undernutrition and } \\
\text { micronutrient deficiencies) }\end{array}$} & Preventive zinc supplementation \\
\hline & Breast feeding \\
\hline & Complementary feeding \\
\hline & Preventive multiple micronutrient (MMN) supplementation \\
\hline \multirow[t]{3}{*}{$\begin{array}{l}\text { Therapeutic nutrition interventions (interventions to treat undernutrition and } \\
\text { micronutrient deficiencies) }\end{array}$} & $\begin{array}{l}\text { Undernutrition/malnutrition [ready-to-use therapeutic food for } \\
\text { community management of severe acute malnutrition] }\end{array}$ \\
\hline & Therapeutic zinc supplementation \\
\hline & Therapeutic MMN supplementation \\
\hline $\begin{array}{l}\text { Fortification strategies (deliberately increasing the content of an essential } \\
\text { micronutrient in food irrespective of whether the nutrients were originally in the } \\
\text { food before processing or not, so as to improve the nutritional quality of the } \\
\text { food supply) }\end{array}$ & Single nutrient fortifications (Folic Acid) \\
\hline Delivery platforms (specific modes and channels of delivering interventions) & Conditional cash transfers \\
\hline
\end{tabular}


domain with respect to their journals, funding, research question, included study designs and meta-analysis, reporting tools, and definition and assessment of outcomes.

\section{Results}

Our search identified 10,926 titles, of which 217 full texts were reviewed and 90 systematic reviews across the nine content areas were included (Figure 1). All eligible texts were available in English, and there was no exclusions based on language. We did not include any unpublished or grey literature review. A wide range of groups were responsible for commissioning and funding the reviews including governments, non-governmental organizations (NGOs), various institutions, UN agencies and private foundations (Table 2). Sixty-eight percent (53/78) of the systematic reviews from the selected nutrition domains were produced from authors based in the high-income countries (HIC) with major contributions from USA, UK, Canada and Australia; thirty-two percent $(25 / 78)$ of the reviews had authors from the LMICs with Pakistan (13/25) being the major contributing site (Figure 2). From the illustrative areas reviewed, the journal publishing the most systematic reviews in the last 5 years in these nine intervention areas was the Cochrane Database of Systematic Reviews (35/90), followed by BioMed Central (7/90), 'Journal of Nutrition' (4/90), 'The Lancet' (4/90), 'American Journal of Clinical Nutrition' (4/90), 'Food and Nutrition Bulletin' (3/90) and 'Journal of
American Medical Association' (3/90) (Figure 3). The included reviews, and overviews of reviews are summarized using the Cochrane public health guideline grid (Table 3). The assessment of the quality of systematic reviews using the AMSTAR rating, and further description of the attributes of the systematic reviews and overviews, are provided below.

\section{Methodological quality-AMSTAR rating}

The median overall AMSTAR score was 8 (range 2-11) with methodological quality of Cochrane reviews being fairly consistent with a median AMSTAR score of 10 (range 8-11), while for the non-Cochrane reviews, it ranged from 2 to 11 with a median of 7.5 (Figure 4). From the 11-point AMSTAR criteria, 91\% (82/90) of the reviews followed an a priori design, $81 \%(73 / 90)$ did duplicate screening and data extraction, 88\% (79/90) conducted comprehensive literature search, 64\% (58/90) used status of publication as an inclusion criteria, $44 \%$ (40/90) provided the list of included and excluded studies, 34\% (31/90) provided the list of included studies only, $74 \%(67 / 90)$ provided characteristics of the included studies, 60\% (54/90) assessed and documented the scientific quality of the included studies and used it in interpreting the results, 61\% (55/90) used appropriate methods to combine the results, $40 \%(36 / 90)$ assessed publication bias and $82 \%(74 / 90)$ stated the conflict of interest.

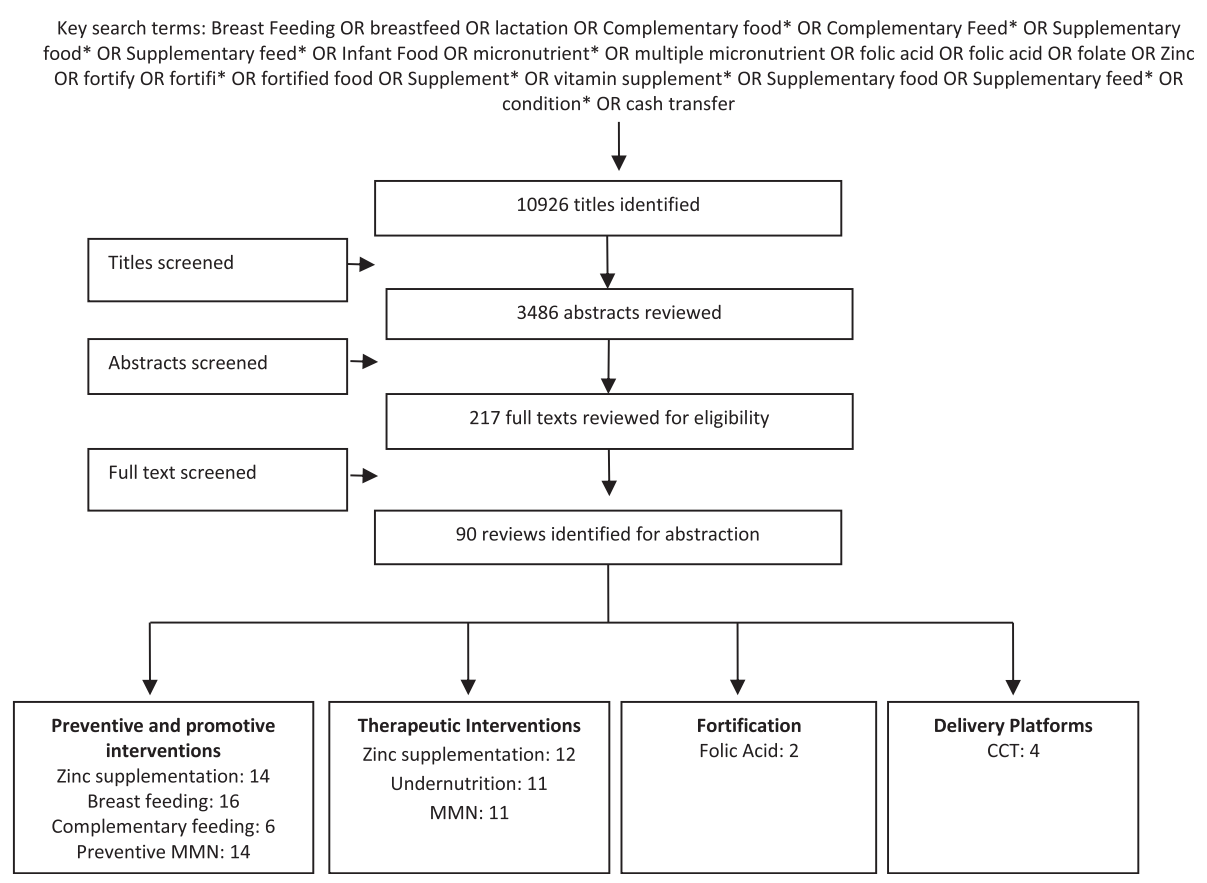

Figure 1 Search flow. 
Table 2 Commissioning and funding of the reviews

\begin{tabular}{|c|c|}
\hline & Organizations \\
\hline Government & $\begin{array}{l}\text { HTA program-HCA; the National Institutes of Health for the prevention of childhood disease; Canadian Institutes of Health } \\
\text { Research; United States Agency for International Development Office of Foreign Disaster Assistance; Research Council of Norway; } \\
\text { Department of Health and Ageing-Australia; USAID; The Department for International Development (UK); UK Department for International } \\
\text { Development (DFID) for developing countries; Concern Worldwide; Ministry of Science and Technological Development, Serbia; Food } \\
\text { Standards Australia New Zealand; Norwegian Agency for Development Cooperation (NORAD) }\end{array}$ \\
\hline UN agencies & WHO, World Bank, UNICEF, World Food Program, United Nations System Standing Committee on Nutrition (SCN) \\
\hline $\begin{array}{l}\text { Private } \\
\text { foundations }\end{array}$ & Bill \& Melinda Gates Foundation, The Richard and Rhoda, Goldman Fund \\
\hline NGOs & $\begin{array}{l}\text { ICDDRB (Bangladesh); The Nutricia Research Foundation; International Initiative for Impact Evaluation; German Technical } \\
\text { Co-operation (GTZ), Germany; Aubrey Sheiham Public Health and Primary Care Scholarship-UK; International Nutrition Council }\end{array}$ \\
\hline Institutions & $\begin{array}{l}\text { The Alberta Heritage; Medical University of Warsaw; The Monsanto Fund; Institute of Child Health, London; Royal College of } \\
\text { Paediatrics and Child Health-UK; The Copenhagen Trial Unit; Harvard Medical School }\end{array}$ \\
\hline
\end{tabular}

\section{Research question}

The research question guides the systematic review and is probably the most important step that defines the population, the intervention, the comparison and the outcomes of interest. We compared research questions for reviews identified on the same intervention to assess for overlap of questions. Although we found several reviews for the same intervention, each review was different because of differences in aspects of the population, intervention, outcome or comparison. For preventive zinc supplementation, two of the included reviews targeted pregnant women, seven targeted children under 5 years of age, one targeted adults while one targeted general population. Besides differences in the target population, reviews evaluated various outcomes; five reviews evaluated childhood infections [30-34], of which three focused on pneumonia alone [31-33]; one on respiratory illness and diarrhoea [30] and one on diarrhoea, pneumonia and malaria altogether [34]. Similarly reviews on multiple micronutrient (MMN) supplementation targeted a variety of age groups including pregnant and women of reproductive age, children, healthy adults, and HIV-infected women and children. Table 4 reports the population, topics and outcomes reported in the included reviews.

\section{Included study designs}

Good quality randomized controlled trials (RCTs) are considered as the highest quality evidence because they minimize the influence of bias in their results; however,

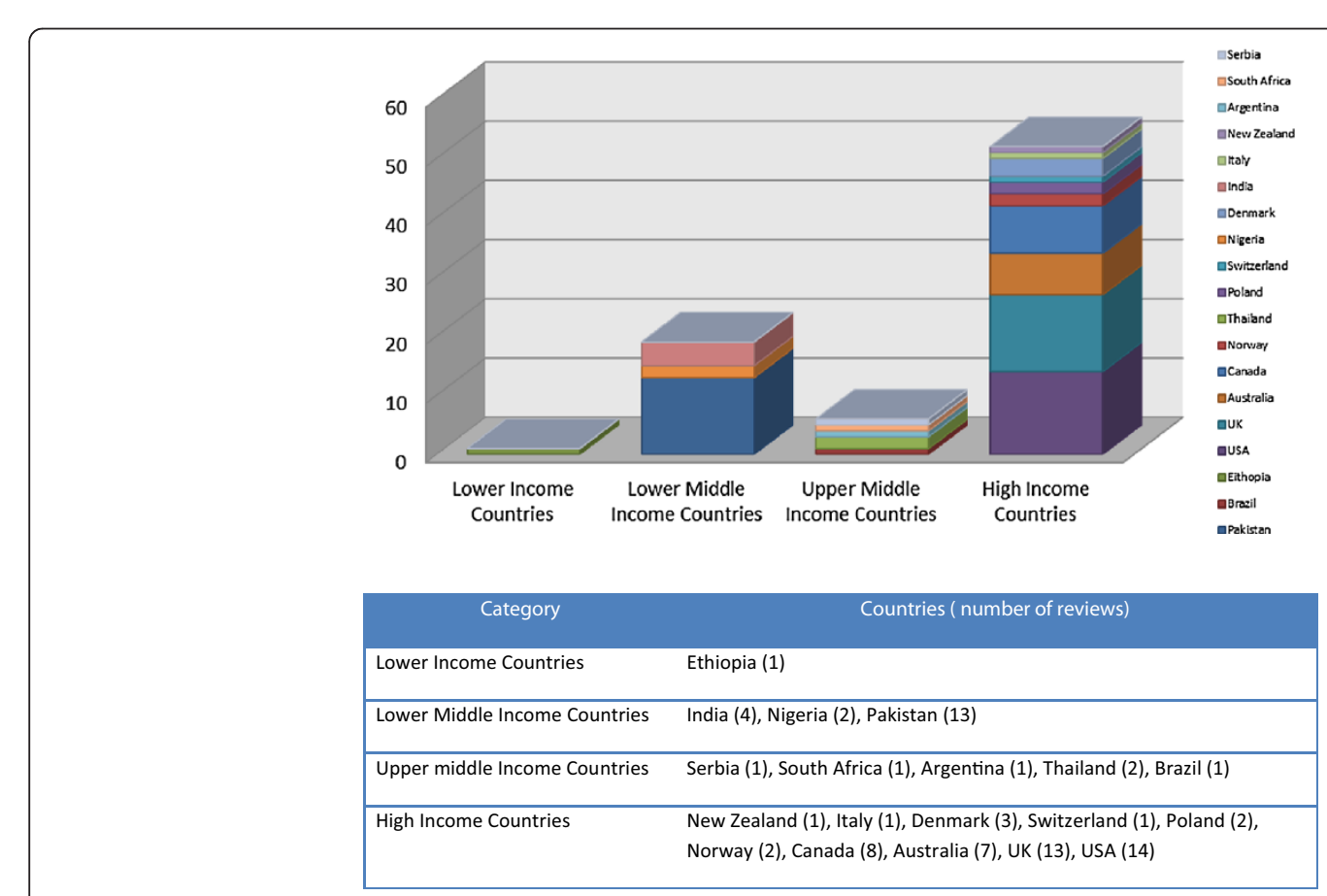

Figure 2 Countries of the lead authors producing reviews. 


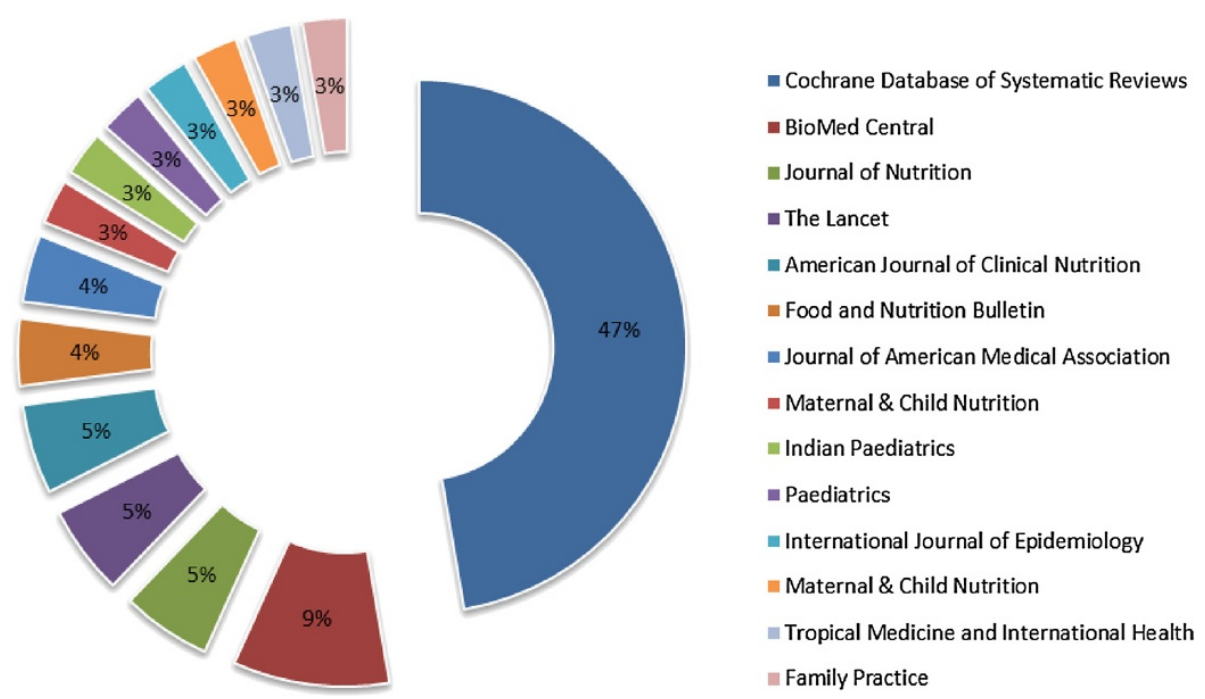

Figure 3 Journals publishing systematic reviews in last 5 years.

RCTs cannot always be relied upon for conducting systematic reviews as such robust study designs account for only $10 \%$ of the healthcare literature $[35,36]$. Within the selected nutrition interventions, we found that 53\% (48/90) of the reviews included RCTs while the others included quasi and observational studies along with RCTs. Most of the Cochrane reviews (73\%) included RCTs and quasi randomized studies; however, for most of the non-Cochrane reviews and some specific interventions like breastfeeding, fortification and management of malnutrition, data from pre-post designs were also included.

\section{Quality assessment of the included studies}

Table 3 specifies the quality assessment tools used by the reviews in each domain. All of the Cochrane reviews used the Cochrane risk of bias tool to assess the methodological quality of included studies, while some non-Cochrane reviews used various quality assessment scales including the CONSORT checklist, Jadad scale, GRADE quality assessment, US Preventive Task Force Quality Rating and Criteria by Glasziou et al. For fortification reviews, methodological quality was assessed using The Food Standards Australia New Zealand (FSAN) framework for assessing evidence when substantiating nutrition, health and related claims on foods. Some reviews mentioned conducting a quality assessment; however, the methodology used was not clear, while information on methodological quality assessment was found missing or unclear in a few reviews. The overview of the reviews used an informal method of quality assessment that is the Oxman et al. 1991 criteria.

\section{Outcomes standardization and assessment}

Standardized, valid outcome measures are pivotal in interpreting findings of systematic reviews, as intervention effectiveness may vary depending on the outcome measurement tools. For example, the specificity of case definitions for acute respiratory infections (ARI) substantially influenced inferences for the effectiveness of preventive and therapeutic interventions [33,37]. Various definitions have been used for defining ARI; however, in some reviews, we found that standardization measures were taken by restricting the inclusion criteria to studies in which ARI case definition aimed to distinguish lower from upper tract respiratory disease; various definitions were also scored for standardization purposes in one of the reviews [33]. Furthermore, despite showing an overall effectiveness of preventive zinc supplementation on pneumonia prevention, the impact changed from statistically significant to non-significant when the definition of pneumonia changed from 'pneumonia defined by specific clinical criteria' to 'lower specificity pneumonia case definition (i.e. age specific fast breathing with or without lower chest in-drawing)' $[31,33]$. Few other reviews reported considerable variation in outcome definition across studies, for example definition of exclusive breastfeeding and mixed breast feeding [38], definitions of diarrhoea $[30,34]$ and the definition of health care workers delivering the interventions [39]. In areas where WHO standard definitions exist like undernutrition, reviews have used standard WHO definitions [40-42], while for some reviews, reviewers have self-defined the outcome for standardization $[43,44]$. Forty three of the included reviews considered contextual factors and conducted sensitivity and subgroup analysis to adjust the outcomes according to these factors.

\section{Meta-analysis and heterogeneity}

Nutrition interventions are inherently complex due to multifaceted interventions, diverse settings and outcomes; 


\section{Methods}

\begin{tabular}{ll}
\hline & Preventive and promotive \\
& interventions ( $n=50)$ \\
& Systematic reviews: \\
& 12Systematic review + \\
& meta: 36Overview: 2 \\
& RCTs: 25 reviewsMixed \\
(RCTs, quasi and other \\
designs): 25 reviews
\end{tabular}

Searching non-
health databases

number seen out of

total (range)

Assessing risk of bias Tools used:Cochrane risk of bias: 17GRADE: $5 \mathrm{Jadad}$ : 1CONSORT: 1Other tools: 18Not stated: 8

Ethics and inequalities

\section{Data from studies}

\section{Therapeutic nutrition} interventions $(n=34)$ Systematic reviews:

10Systematic review + meta: 24Overview: 0

RCTs: 23 reviewsMixed (RCTs, quasi and other designs): 11 reviews

\section{Fortification}

acid) $(n=2)$

OSystematic review. $\quad$ Systematic reviews:

meta: 2Overview: 0 meta: 0Overview: 1

RCTs: 0 reviewsMixed RCTs: 0 reviewsMixed (RCTs, quasi and

Other designs): 2
reviewsOverview: 0 reviews

0
$11(1-2)$

(RCTs, quasi and other designs): 4 reviews

RCTs may have limited

generalizability or not be feasible

or ethical. Non-randomized trials

or cluster RCTs may be more

appropriate for the question

Public health may require range of databases and detailed text words because terminology is imprecise

Tools used:Cochrane risk Tools used:Cochrane Tools used:Cochrane of bias: 14GRADE: OJadad: risk of bias: OGRADE: risk of bias: 2GRADE: OCONSORT: 0Other tools: 1 Jadad: OCONSORT: 19Not stated: 1 OOther tools: 1

HIC: 8LMIC: 15Both: 11 OJadad: OCONSORT:

$3(3-5)$

HIC: OLMIC: 2Both: 2
Context (explore

context as an effect

modifier)

\section{Sustainability}

(sustainability was

assessed or

described)

Applicability

(conducted

subgroup analysis to

assess applicability

to different settings)

HIC high-income countries, LMIC low-middle-income countries, $R C T$ randomized controlled trials.

Appraisal criteria depend on the type of study in the review. Authors should use Cochrane risk of bias tool for RCTs

Public health interventions may unintentionally increase health inequalities if the more advantaged benefit more than the worst off. Authors should consider whether populations are likely to be disadvantaged across PROGRESS+ acronym factors (place of residence, race or ethnicity, occupation, gender, religion, education, socioeconomic position (SES) and social capital

Public health interventions depend on social, economic and political context in which they are developed and implemented. Context should be explored as an effect modifier (e.g. host organization, target population)

Consider the extent to which the intervention's effects on outcomes are sustained over time, e.g. by assessing economic and political variables, strength of implementing institutions, integration of services into existing services, training component, community involvement

Authors are well-positioned to collect data needed to make judgments about applicability to different settings, including political environment, social norms, cultural preferences, resources required, educational level of target population, organizational capacity to deliver the intervention, structural barriers to intervention, health care providers have capacity to deliver this intervention 


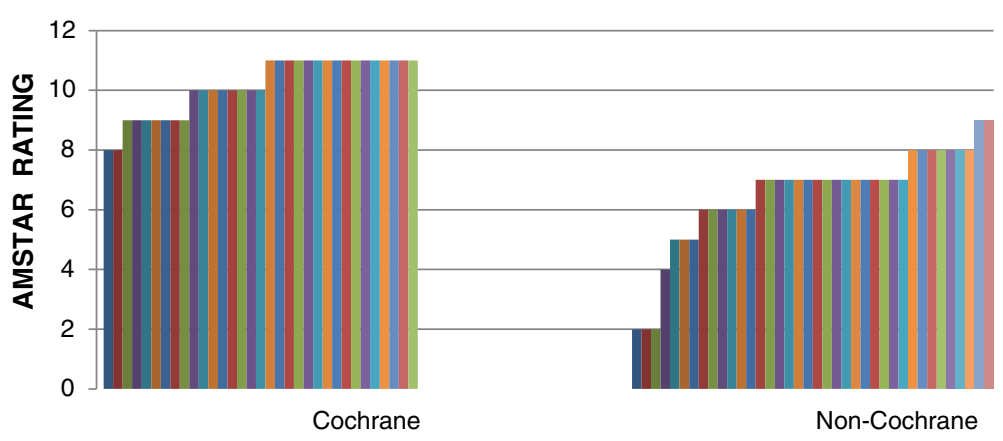

Figure 4 AMSTAR ratings for the included Cochrane and non-Cochrane reviews.

hence, it is challenging to pool data for meta-analysis which leads to a lack of consensus on effectiveness and contradicting findings. Almost all the reviews reported heterogeneity in the data. Out of 90 included reviews, 62 were systematic reviews with a meta-analysis, 25 were systematic reviews without meta-analysis, while almost $11 \%$ $(10 / 90)$ of the systematic reviews reported heterogeneity as a reason for not conducting meta-analysis. The heterogeneity reported was both clinical as well as statistical due to diverse interventions, target population and outcome definitions. None of the reviews conducted meta-analysis using individual patient data (IPD).

\section{Discussion}

Our overview findings pertain to the process and conduct of systematic reviews and not individual studies since we did not assess the primary studies. Our findings suggest that from the 90 nutrition-related reviews, we found considerable variation in methodological quality as assessed by the AMSTAR (ranging from 2 to 11), lack of standardization of outcomes, lack of standardized assessment of risk of bias of included studies, variation in study designs included and variation in how heterogeneity was handled. Each of these methodological choices influence the findings of the reviews, and lack of standardization across these domains increases the complexity for users of systematic reviews in interpreting results-sometimes of conflicting reviews. None of the included meta-analyses used IPD, which provides more detailed analyses and a broader methodological scope due to the presence of raw data. Our analysis shows that these nutrition reviews are comparable to a random sample of systematic reviews across all topics. However, the sample of nutrition reviews had considerably more reviews led by an LMIC author, 32\% compared to the 2004 sample where $<20 \%$ of all reviews had the contact author outside of USA, UK, Canada, New Zealand and Germany [45]. Systematic reviews and meta-analysis have become increasingly popular in evidence-based healthcare over the past two decades [16-20]. The selected systematic reviews on nutrition came from varying sources as the nutrition-related interventions are not solely implemented by health sector. There is an evident gap of quantitative data in some major areas concerning nutrition like undernutrition that direly needs policy guidance. We found considerable overlap between the topics and questions addressed in multiple reviews; however, the outcomes reported varied.

Overall, the methodological quality of the Cochrane reviews was found to be better, which is not surprising since they are conducted according to standardized guidelines published in the 'Cochrane Handbook'. However, within the Cochrane Collaboration, several editorial groups have undertaken nutrition-related reviews, and while the broad methods are consistent, there is variability in nutrition-specific decisions about the methods such as eligibility criteria for population, intervention, comparison and outcomes and consideration of contextual variables. Furthermore, in some areas like conditional cash transfers (CCTs), the scope is very broad and thus fails to focus on nutrition-specific indicators. There is a need for improved justification of methodological choices in nutrition systematic reviews. We propose the need to follow standards for conducting systematic reviews such as the 'Cochrane Handbook' [46], as well as the Preferred Reporting Items for Systematic Reviews and Meta-Analyses (PRISMA) guidelines for reporting systematic reviews and meta-analyses [47]. With respect to public health nutrition, there is a need for standardization in defining of the population, intervention, comparison and outcomes, as well as a need for attention to aspects of context, appropriate study designs, sustainability and applicability. For outcomes, there is a need to standardize the measurement and definition of outcomes. The Core Outcome Measures in Effectiveness Trials (COMET) initiative is a major opportunity to explore this for nutrition. The differences in methods used are consistently observed in both Cochrane and non-Cochrane reviews, suggesting a need for improved guidance for nutrition reviews. 
Table 4 Population, topics and outcomes reported in the included reviews

\begin{tabular}{|c|c|c|c|c|c|}
\hline Intervention & $\begin{array}{l}N \\
\text { (Cochrane/ } \\
\text { non- } \\
\text { Cochrane) }\end{array}$ & Population & Topics & Outcomes & Setting \\
\hline Preventive zinc & $14(7 / 7)$ & $\begin{array}{l}\text { Pregnancy (2)Children }<5 \text { (7) } \\
\text { Adult (1)General population (1) }\end{array}$ & $\begin{array}{l}\text { Supplementation during } \\
\text { pregnancy and outcome } \\
\text { assessment: } 2 \\
\text { Supplementation to } \\
\text { children under five and } \\
\text { impact on growth: } 2 \\
\text { Supplementation to } \\
\text { children and impact on } \\
\text { infections: } 4\end{array}$ & $\begin{array}{l}\text {-Anthropometric Indices } \\
\text {-APGAR•All-cause mortality } \\
\text {-Age-specific mortality } \\
\text {-Cause-specific mortality } \\
\text { (diarrhoea, pneumonia) } \\
\text {-Neonatal (birth weight, } \\
\text { linear growth) } \\
\text {-Morbidity (incidence and } \\
\text { duration of ARI, diabetes, } \\
\text { otitis media) } \\
\text {-Haemoglobin level }\end{array}$ & $\begin{array}{l}\operatorname{LMIC}(n=8) \\
\text { HIC }(n=1) \text { Both } \\
(n=2)\end{array}$ \\
\hline Breast feeding & $16(11 / 05)$ & $\begin{array}{l}\text { Pregnant }+ \text { reproductive age } \\
\text { woman (7)Children (5)General } \\
\text { population (2) }\end{array}$ & $\begin{array}{l}\text { Interventions to promote } \\
\text { breast feeding: } 6\end{array}$ & $\begin{array}{l}\text {-Initiation, duration and } \\
\text { exclusive } \\
\text { breast feeding } \\
\text {-Neonatal and infant } \\
\text { morbidities } \\
\text {-Anthropometric indices } \\
\text { - Maternal satisfaction } \\
\text {-Cognitive development } \\
\text { - Neonatal mortality } \\
\text {-Micronutrient status } \\
\text {-Maternal weight loss } \\
\text { - Breast and ovarian cancer } \\
\text { - Osteoporosis } \\
\text {-Pain } \\
\text { - Maternal morbidities }\end{array}$ & $\begin{array}{l}\text { LMIC }(n=1) \\
\text { HIC }(n=6) \\
\text { Both }(n=4) \\
\text { Not clear (2) }\end{array}$ \\
\hline $\begin{array}{l}\text { Complementary } \\
\text { feeding }\end{array}$ & $06(1 / 5)$ & Children (6) & $\begin{array}{l}\text { Education and counselling } \\
\text { interventions to promote } \\
\text { complementary feeding: } 5\end{array}$ & $\begin{array}{l}\text {-Anthropometric indices } \\
\text {-Micronutrient intake and } \\
\text { status } \\
\text {-Morbidity }\end{array}$ & LMIC $(n=6)$ \\
\hline $\begin{array}{l}\text { Preventive } \\
\text { multiple } \\
\text { micronutrient } \\
\text { supplementation }\end{array}$ & $14(4 / 10)$ & $\begin{array}{l}\text { Pregnant + reproductive age } \\
\text { woman (6)Children (2)Women } \\
\text { and children (4)Adult men (1) }\end{array}$ & $\begin{array}{l}\text { Supplementation during } \\
\text { and prior to pregnancy } \\
\text { and its impact on pregnancy } \\
\text { outcome: } 9 \\
\text { Supplementation to } \\
\text { HIV-infected women and } \\
\text { children: } 2\end{array}$ & $\begin{array}{l}\text {-Birth weight } \\
\text {-Kwashiorkor } \\
\text {-Prematurity, SGA, LBW } \\
\text {-Stillbirth, neonatal and } \\
\text { perinatal mortality } \\
\text {-Premature rupture of membranes } \\
\text {-Preeclampsia } \\
\text {-Miscarriage } \\
\text {-Congenital anomalies } \\
\text { - Nutritional status } \\
\text {-Micronutrient level } \\
\text {-Maternal anaemia } \\
\text {-Multiple pregnancies } \\
\text { - Psychological effects } \\
\text {-HIV transmission and viral load } \\
\text {-Prostate cancer occurrence, } \\
\text { metastasis, mortality }\end{array}$ & $\begin{array}{l}\text { LMIC }(n=4) \\
\text { HIC }(n=2) \\
\text { Both }(n=4) \\
\text { Not clear (3) }\end{array}$ \\
\hline Therapeutic zinc & $12(4 / 8)$ & $\begin{array}{l}\text { Children (6)General population } \\
\text { (5)Adult (1) }\end{array}$ & $\begin{array}{l}\text { Adult supplementation } \\
\text { and its impact on cold } \\
\text { symptoms: } 2 \\
\text { Supplementation among } \\
\text { children and impact on } \\
\text { diarrhoea and pneumonia: } 6\end{array}$ & $\begin{array}{l}\text {-Ulcer healing (time, rate) } \\
\text {-Incidence, severity and } \\
\text { duration of cold } \\
\text {-Pneumonia: incidence, duration } \\
\text { and recurrence of pneumonia. } \\
\text { Recovery time and hospitalization } \\
\text { - Adverse effects } \\
\text { - Lipid profile } \\
\text {-Incidence and duration of } \\
\text { malaria and TB } \\
\text { - Hospital stay, cost and mortality } \\
\text { of critically ill patients }\end{array}$ & $\begin{array}{l}\text { LMIC }(n=3) \\
\text { HIC }(n=4) \\
\text { Both }(n=3) \\
\text { Not clear (2) }\end{array}$ \\
\hline $\begin{array}{l}\text { Interventions for } \\
\text { undernutrition }\end{array}$ & $11(4 / 7)$ & Children (11) & $\begin{array}{l}\text { Management of under } \\
\text { nutrition through } \\
\text { supplementary feeding: } 9\end{array}$ & $\begin{array}{l}\text {-Kwashiorkor } \\
\text {-Cognitive development } \\
\text {-Hospitalization }\end{array}$ & LMIC $(n=11)$ \\
\hline
\end{tabular}


Table 4 Population, topics and outcomes reported in the included reviews (Continued)

\begin{tabular}{|c|c|c|c|c|c|}
\hline & & & & $\begin{array}{l}\text {-Anthropometric indices } \\
\text {-Recurrent illnesses } \\
\text {-Mortality } \\
\text {-HIV prevalence and mortality } \\
\text {-Morbidity: diarrhoea, malaria } \\
\text { and ARI } \\
\text {-Maternal knowledge, anxiety }\end{array}$ & \\
\hline $\begin{array}{l}\text { Therapeutic } \\
\text { multiple } \\
\text { micronutrient } \\
\text { supplementation }\end{array}$ & $11(3 / 8)$ & $\begin{array}{l}\text { Children (1)Adults (4)Adult Men } \\
\text { (1)Population with HIV (4) }\end{array}$ & HIV-infected populations: 5 & $\begin{array}{l}\text {-Infant mortality } \\
\text {-Anthropometric indices } \\
\text {-Micronutrient levels } \\
\text {-Anaemia } \\
\text {-Mental and motor development } \\
\text {-Pregnancy outcomes } \\
\text {-HIV progression, transmission } \\
\text { and viral load } \\
\text {-HIV hospitalization, morbidity } \\
\text { and mortality } \\
\text { - Fasting glucose and insulin } \\
\text { resistance } \\
\text {-Treatment and length of } \\
\text { hospitalization of TB } \\
\text {-Age-related disorders like } \\
\text { age-related macular degeneration } \\
\text { and cataract } \\
\text {-Occurrence, metastasis and } \\
\text { mortality due to prostate cancer }\end{array}$ & $\begin{array}{l}\text { LMIC }(n=1) \\
\text { HIC }(n=2) \\
\text { Both }(n=4) \\
\text { Not clear }(4)\end{array}$ \\
\hline $\begin{array}{l}\text { Fortification (folic } \\
\text { acid) }\end{array}$ & $02(0 / 2)$ & $\begin{array}{l}\text { Pregnant and women of } \\
\text { reproductive age (1)General } \\
\text { population (1) }\end{array}$ & & $\begin{array}{l}\text {-Neural tube defect } \\
\text {-Neonatal mortality for NTD } \\
\text {-Twining }\end{array}$ & Both $(n=2)$ \\
\hline $\begin{array}{l}\text { Conditional cash } \\
\text { transfers (CCT) }\end{array}$ & $4(1 / 3)$ & General population (4) & $\begin{array}{l}\text { All } 4 \text { reviews assessed the } \\
\text { impact CCT on health } \\
\text { outcomes }\end{array}$ & $\begin{array}{l}\text {-Coverage of health service } \\
\text {-Access to health care } \\
\text {-Household health expenditure } \\
\text { - Nutritional outcomes }\end{array}$ & $\begin{array}{l}\operatorname{LMIC}(n=2) \\
\text { Both }(n=2)\end{array}$ \\
\hline
\end{tabular}

HIC high-income countries, LMIC low-middle-income countries, NTD neural tube defect.

Existing evidence related to systematic review conduct in the field of nutrition highlight the fact that systematic reviews in nutrition are unique and challenging as it encompasses various nutrition-related considerations including baseline nutrient exposure, nutrient status, bioequivalence of bioactive compounds, bioavailability, multiple and interrelated biological functions, undefined nature of some interventions and uncertainties in assessment [23]. Developing capacitybuilding programmes, searching the primary literature for research gaps and extending reporting tools such as the PRISMA Statement to the field of nutrition are recommended to improve the conduct of systematic reviews in nutrition $[48,49]$.

One strength of this paper is the assessment of methods used in systematic reviews of nutrition using accepted tools including the AMSTAR and the 'Cochrane Handbook of Public Health Guidance'. One limitation is that we used a non-validated search for nutrition topics and thus may have missed some systematic reviews. However, we think this limitation is unlikely to affect the findings of this study since we intended to identify a purposive sample, rather than an exhaustive sample of systematic reviews in nine intervention areas. Furthermore, our assessment of quality of the included systematic reviews is limited to how they were reported.

Given the growth in the field, there is a clear need to develop a consensus on methodologies for nutrition reviews, criteria for assessing the evidence and possibly facilitating development and collation of the evidence in the subject area. There also needs to be clarity on the purpose of the reviews and on the questions that they are addressing, for them to be useful in the context of programme and policy guidance. The diverse methods involved in such systematic evidence syntheses and conclusions thereof have a clear bearing on impact on policy and practice. Given the differing needs of information syntheses by practitioners and public sector policymakers, a consensus on the quality indicators for such reviews and methods is an important prerequisite. While the Cochrane and Campbell collaborations have a due process with published guidelines within the 'Cochrane Handbook', other journals and peer review processes may not follow a standard set of criteria. Cochrane and Campbell are wellpositioned to take the lead in improving quality as our analysis also suggests that the quality ratings for the 
Cochrane reviews were found to be fairly consistent as compared to the non-Cochrane reviews. The Campbell International Development Nutrition group is actively working on these priority areas of methodological quality, outcome standardization and avoiding duplication. Engagement with a range of stakeholders could lead to wider uptake and endorsement of such standards and priorities. This could then expand to include guidance to other journals and agencies evaluating and publishing nutrition-related systematic reviews.

\section{Conclusions}

To conclude, there is a need to develop a consensus on methodologies for nutrition reviews, criteria for assessing the evidence and possibly facilitating development and collation of the evidence in the subject area. We therefore propose the development of a potential nutrition review editorial process and a group inclusive of major stakeholders in the field to help bring the field together.

\begin{abstract}
Abbreviations
AMSTAR: Assessment of Multiple Systematic Reviews; COMET: Core Outcome Measures in Effectiveness Trials; DFID: Department of International Development; EPPI: Evidence for Policy, Practice Information and Coordinating Centre; FAO: Food and Agriculture Organization; MeSH: Medical Subject Headings; MMN: Multiple micronutrient; OMERACT: Outcome Measures in Rheumatoid Arthritis Clinical Trials; OR: Odds ratio; PICO: Participants, Intervention, Comparison and Outcome; PRISMA: Preferred Reporting Items for Systematic Reviews and Meta-Analyses; RCT: Randomized controlled trial; RR: Relative risk; RUTF: Ready-to-use therapeutic food; SAM: Severe acute malnutrition; SMD: Standard mean difference; SOFI: State of Food Security; UN: United Nations; UNICEF: United Nations International Children's Emergency Fund; USAID: United States Agency for International Development; WFP: World Food Program; WHO: World Health Organization.
\end{abstract}

\section{Competing interests}

The authors declare that they have no competing interests.

\begin{abstract}
Authors' contributions
ZAB was responsible for designing and coordinating the review. WW was responsible for the methodological and quality assessment of the reviews. RAS was responsible for data collection, screening the search results, screening retrieved papers against inclusion criteria, appraising quality of papers and abstracting data from papers. All the authors contributed towards writing the manuscript. All authors read and approved the final manuscript.
\end{abstract}

\section{Acknowledgements}

We would like to acknowledge the academic groups, editors of the Cochrane and Campbell collaborations, 3ie, UN agencies (WHO, UNICEF, WFP, FAO), IFPRI and other bilateral agencies (notably DFID, USAID, NORAD) and representatives from the Bill \& Melinda Gates Foundation for funding the work and consultation to guide this study. We would also like to acknowledge Omer Bangash, who helped us with the double data extractions.

\footnotetext{
Author details

${ }^{1}$ Center of Excellence in Women and Child Health, Division of Woman and Child Health, Aga Khan University, Karachi 74800, Pakistan. ${ }^{2}$ Centre for Global Health, University of Ottawa, Ottawa, Canada. ${ }^{3}$ Robert Harding Chair in Global Child Health and Policy, Centre for Global Child Health, The Hospital for Sick Children, Toronto, ON, Canada.
}

Received: 19 September 2014 Accepted: 5 February 2015 Published online: 13 April 2015

\section{References}

1. Global Alliance for Improved Nutrition 2014. Highlighting recent advances in understanding the bioavailability of micronutrients. Available at http:// www.gainhealth.org/knowledge-centre/highlighting-recent-advancesunderstanding-bioavailability-micronutrients/.

2. Shah PS, Aliwalas LL, Shah V. Breastfeeding or breast milk for procedural pain in neonates. Cochrane Database Syst Rev. 2006;12(12):CD004950.

3. Bhutta ZA, Salam RA. Global nutrition epidemiology and trends. Ann Nutr Metab. 2012;61(1):19-27.

4. Bhutta ZA. Micronutrient needs of malnourished children. Curr Opin Clin Nutr Metab Care. 2008;11(3):309-14.

5. World Health O. Severe malnutrition: report of a consultation to review current literature. Geneva: World Health Organization; 2005.

6. Black RE, Victora CG, Walker SP, Bhutta ZA, Christian P, de Onis M, et al. Maternal and child undernutrition and overweight in low-income and middle-income countries. Lancet. 2013;382(9890):427-51.

7. Black RE, Allen LH, Bhutta ZA, Caulfield LE, De Onis M, Ezzati M, et al. Maternal and child undernutrition: global and regional exposures and health consequences. Lancet. 2008:371(9608):243-60.

8. Victora CG, Adair L, Fall C, Hallal PC, Martorell R, Richter L, et al. Maternal and child undernutrition: consequences for adult health and human capital. Lancet. 2008;371(9609):340.

9. Bhutta ZA, Ahmed T, Black RE, Cousens S, Dewey K, Giugliani E, et al. Maternal and child undernutrition 3: what works? Interventions for maternal and child undernutrition and survival. Child-Care Health Dev. 2008;34(3):404-404.

10. Bloomberg JH. Maternal and child undernutrition 4. Maternal and child undernutrition: effective action at national level. Lancet. 2008;371:510-26.

11. Morris SS, Cogill B, Uauy R. Effective international action against undernutrition: why has it proven so difficult and what can be done to accelerate progress? Lancet. 2008;371(9612):608-21.

12. Bhutta ZA, Das JK, Rizvi A, Gaffey MF, Walker N, Horton S, et al. Evidence-based interventions for improvement of maternal and child nutrition: what can be done and at what cost? Lancet. 2013;382(9890):452-77.

13. Gillespie S, Haddad L, Mannar V, Menon P, Nisbett N. The politics of reducing malnutrition: building commitment and accelerating progress. Lancet. 2013;382(9891):552-69.

14. Ruel MT, Alderman H. Nutrition-sensitive interventions and programmes: how can they help to accelerate progress in improving maternal and child nutrition? Lancet. 2013;382(9891):536-51.

15. The World Bank. Fragility and Conflict. Accessed from http://wbi. worldbank.org/wbi/about/topics/fragile-states.

16. Lavis J, Davies H, Oxman A, Denis JL, Golden-Biddle K, Ferlie E. Towards systematic reviews that inform health care management and policy-making. J Health Serv Res Policy. 2005;10 Suppl 1:35-48.

17. Furukawa TA, Streiner DL, Hori S. Discrepancies among megatrials. J Clin Epidemiol. 2000;53(12):1193-9.

18. LeLorier J, Gregoire G, Benhaddad A, Lapierre J, Derderian F. Discrepancies between meta-analyses and subsequent large randomized, controlled trials. N Engl J Med. 1997;337(8):536-42.

19. Trikalinos TA, Moorthy D, Chung M, Yu WW, Lee J, Lichtenstein AH, Lau J: Concordance of randomized and nonrandomized studies was unrelated to translational patterns of two nutrient-disease associations. J Clin Epidemiol. 2012;65(1):16-29.

20. Villar J, Carroli G, Belizan JM. Predictive ability of meta-analyses of randomised controlled trials. Lancet. 1995;345(8952):772-6.

21. Cook DJ, Greengold NL, Ellrodt AG, Weingarten SR. The relation between systematic reviews and practice guidelines. Ann Intern Med. 1997;127(3):210-6.

22. Lavis JN, Posada FB, Haines A, Osei E. Use of research to inform public policymaking. Lancet. 2004;364(9445):1615-21.

23. Lichtenstein AH, Yetley EA, Lau J. Application of systematic review methodology to the field of nutrition. (Prepared by the Tufts Evidence-based Practice Center under Contract No. 290-020022). AHRQ publication No. 09-0025. Rockville, MD: Agency for Healthcare Research and Quality; 2009. Available at http://www.ncbi.nlm.nih.gov/books/NBK44076/pdf/TOC.pdf.

24. Tugwell P, Petticrew M, Kristjansson E, Welch V, Ueffing E, Waters E, et al. Assessing equity in systematic reviews: realising the recommendations 
of the Commission on Social Determinants of Health. BMJ. 2010; 341:c4739.

25. WHO. e-Library of Evidence for Nutrition Actions (eLENA). Access from http://www.who.int/elena/en/.

26. WHO. Use of systematic reviews of the evidence in public health nutrition Proceedings of an informal consultation held 18 October 2011 in Geneva, Switzerland. Geneva: World Health Organization; 2013. Available at http:// apps.who.int/iris/bitstream/10665/85792/1/9789241506038_eng.pdf.

27. Higgins JPT, Green S (editors). Cochrane Handbook for Systematic Reviews of Interventions Version 5.1.0 [updated March 2011]. The Cochrane Collaboration, 2011. Available from www.cochrane-handbook.org

28. Systematic Reviews of Health Promotion and Public Health Interventions. http://ph.cochrane.org/sites/ph.cochrane.org/files/uploads/Guidelines\% 20HP_PH\%20reviews.pdf.

29. Shea B, Grimshaw J, Wells G, Boers M, Andersson N, Hamel C, et al. Development of AMSTAR: a measurement tool to assess the methodological quality of systematic reviews. BMC Med Res Methodol. 2007;7(1):10.

30. Aggarwal R, Sentz J, Miller MA. Role of zinc administration in prevention of childhood diarrhea and respiratory illnesses: a meta-analysis. Pediatrics. 2007;119(6):1120.

31. Lassi ZS, Haider BA, Bhutta ZA. Zinc supplementation for the prevention of pneumonia in children aged 2 months to 59 months. Cochrane Database Syst Rev. 2010;12(12):CD005978.

32. Mathew JL. Zinc supplementation for prevention or treatment of childhood pneumonia: a systematic review of randomized controlled trials. Indian Pediatr. 2010;47(1):61-6.

33. Roth DE, Richard SA, Black RE. Zinc supplementation for the prevention of acute lower respiratory infection in children in developing countries: meta-analysis and meta-regression of randomized trials. Int J Epidemiol. 2010;39(3):795.

34. Yakoob MY, Theodoratou E, Jabeen A, Imdad A, Eisele T, Ferguson J, et al. Preventive zinc supplementation in developing countries: impact on mortality and morbidity due to diarrhea, pneumonia and malaria. BMC Public Health. 2011;11 Suppl 3:S23.

35. Funai EF, Rosenbush EJ, Lee MJ, Del Priore G. Distribution of study designs in four major US journals of obstetrics and gynecology. Gynecol Obstet Invest. 2001;51(1):8-11.

36. Scales Jr CD, Norris RD, Peterson BL, Preminger GM, Dahm P. Clinical research and statistical methods in the urology literature. J Urol. 2005;174(4 Pt 1):1374-9.

37. Rudan I, Tomaskovic L, Boschi-Pinto C, Campbell H. Global estimate of the incidence of clinical pneumonia among children under five years of age. Bull World Health Organ. 2004;82(12):895-903.

38. Kramer MS, Kakuma R. Optimal duration of exclusive breastfeeding. Cochrane Database Syst Rev. 2002;1 (1):CD003517.

39. Lewin S, Munabi Babigumira S, Glenton C, Daniels K, Bosch Capblanch X, Van Wyk BE, et al. Lay health workers in primary and community health care for maternal and child health and the management of infectious diseases. Cochrane Database Syst Rev. 2010;3(3):CD004015.

40. Dewey KG, Adu Afarwuah S. Systematic review of the efficacy and effectiveness of complementary feeding interventions in developing countries. Maternal Child Nutr. 2008;4:24-85.

41. Imdad A, Sadiq K, Bhutta ZA. Evidence-based prevention of childhood malnutrition. Curr Opin Clin Nutr Metab Care. 2011;14(3):276.

42. Shi L, Zhang J. Recent evidence of the effectiveness of educational interventions for improving complementary feeding practices in developing countries. J Trop Pediatr. 2010;57(2):91

43. Lagarde M, Haines A, Palmer N. Conditional cash transfers for improving uptake of health interventions in low-and middle-income countries. JAMA. 2007;298(16):1900

44. Lagarde $\mathrm{M}$, Haines $\mathrm{A}$, Palmer $\mathrm{N}$. The impact of conditional cash transfers on health outcomes and use of health services in low and middle income countries. Cochrane Database Syst Rev. 2009:4(4):CD008137.

45. Moher D, Tetzlaff J, Tricco AC, Sampson M, Altman DG. Epidemiology and reporting characteristics of systematic reviews. PLoS Med. 2007;4(3):e78.

46. Higgins JPT, Green S (editors). Cochrane Handbook for Systematic Reviews of Interventions Version 5.1.0 [updated March 2011]. The Cochrane Collaboration, 2011. Available from www.cochrane-handbook.org.
47. Moher D, Liberati A, Tetzlaff J, Altman DG, The PRISMA Group. Preferred reporting items for systematic reviews and meta-analyses: the PRISMA statement. PLoS Med. 2009;6(7):e1000097.

48. Moher D, Tricco AC. Issues related to the conduct of systematic reviews: a focus on the nutrition field. Am J Clin Nutr. 2008;88(5):1191-9.

49. Lichtenstein $\mathrm{AH}$, Elizabeth $\mathrm{AY}$, Joseph L. Application of systematic review methodology to the field of nutrition. J Nutr. 2008;12(138):2297-306.

\section{Submit your next manuscript to BioMed Central and take full advantage of:}

- Convenient online submission

- Thorough peer review

- No space constraints or color figure charges

- Immediate publication on acceptance

- Inclusion in PubMed, CAS, Scopus and Google Scholar

- Research which is freely available for redistribution 